\title{
PERFIL FÍSICO-QUÍMICO DE QUEIJOS ARTESANAIS DO NORTE DE MINAS GERAIS
}

\author{
Physical-chemical profile of artisanal cheeses from northern Minas Gerais
}

\author{
Lilian Ferreira Neves ${ }^{1}$ \\ Hugo Calixto Fonseca ${ }^{2}$ \\ Mariuze Loyanny Pereira Oliveira ${ }^{3}$ \\ Cintya Neves de Souza ${ }^{4}$ \\ Grayce Laiz Lima Silveira Durães ${ }^{5}$ \\ Eduardo Robson Duarte ${ }^{6}$ \\ Marcelo Resende de Souza ${ }^{7}$
}

Resumo: A produção de queijos a partir de leite cru é uma atividade tradicional em vários municípios de Minas Gerais. Visando contribuir com informações sobre esse produto, tido como patrimônio cultural do Estado. Objetivo: Foi realizar análises físico-químicas em queijos artesanais produzidos em regiões do Norte de Minas - MG. Método: Foram analisadas 15 amostras de queijos de diferentes cidades do norte de Minas Gerais; as análises

\footnotetext{
${ }^{1}$ Mestre em Produção Animal pela Universidade Federal de Minas Gerais (UFMG). Montes Claros/MG- Brasil.. $\triangle$ lilianeves2019@gmail.com. (D) https://orcid.org/0000-0002-3690-1252.

${ }^{2}$ Doutor em Ciência dos Alimentos pela Universidade Federal de Lavras (UFLA). Lavras/MG- Brasil. $\square$ hugocfonseca@yahoo.com.br. .https://orcid.org/0000-0001-6410-4253.

${ }_{3}^{3}$ Mestranda em Alimentos e Saúde pela Universidade Federal de Minas Gerais (UFMG). Montes Claros/MGBrasil. $₫$ mariuzelpe@yahoo.com.br. (i) https://orcid.org/0000-0002-9441-3054.

${ }^{4}$ Doutoranda em Microbiologia pela Universidade Federal de Minas Gerais (UFMG). Belo Horizonte/MGBrasil. $\square$ cintyamicro@hotmail.com. (D) https://orcid.org/0000-0002-3640-8636.

${ }^{5}$ Mestre em Produção Animal pela Universidade Federal de Minas Gerais (UFMG). Montes Claros/MG- Brasil. $\triangle$ laizgrayce@yahoo.com.br. (iD) https://orcid.org/0000-0002-9860-2821.

${ }^{6}$ Doutor em Ciências Biológicas pela Universidade Federal de Minas Gerais (UFMG). Belo Horizonte/MGBrasil. $₫$ duartevet@hotmail.com. (D) https://orcid.org/0000-0002-2205-9412.

${ }^{7}$ Doutor em Ciências Biológicas pela Universidade Federal de Minas Gerais (UFMG). Belo Horizonte/MGBrasil.. $\triangle$ marceloresende51@gmail.com. (D) https://orcid.org/0000-0001-7071-7304.
}

$\begin{array}{ccc}\text { Recebido em } & \text { Aceito em } & \text { Publicado em } \\ 28 / 04 / 2021 & 21 / 06 / 2021 & 02 / 07 / 2021\end{array}$


de $\mathrm{pH}$, acidez titulável, umidade, teor de proteínas, gordura e gordura no extrato seco (GES) foram realizadas pelos métodos oficiais de acordo com a legislação vigente. Resultados: Demonstraram variações significativas quanto aos teores de lipídios (20,6 a 26,66\%), e proteínas (14,27 a 23,10\%). Conclusão: Apesar de ter sido analisado o mesmo tipo de queijo, as variações observadas para os queijos produzidos nas diferentes regiões podem ser decorrentes das particularidades de produção, bem como das características de cada região.

Palavras chave: queijo artesanal; composição; qualidade.

Abstract: The production of cheese from raw milk is a traditional activity in several municipalities in Minas Gerais. Aiming to contribute with information about this product, considered as cultural heritage of the State, the objective of the study was to carry out physicochemical analyzes in artisanal cheeses produced in regions of the North of Minas MG. Fifteen cheese samples from different cities in the north of Minas Gerais were analyzed; $\mathrm{pH}$, titratable acidity, moisture, protein, fat and fat in dry extract GES were analyzed using official methods in accordance with current legislation. The results showed significant variations in terms of lipids (20.6 to $26.66 \%$ ) and proteins (14.27 to $23.10 \%$ ). Although the same type of cheese was analyzed, the variations observed for cheeses produced in different regions may be due to the particularities of production, as well as the characteristics of each region.

Key words: artisanal cheese; composition; quality.

\section{INTRODUÇÃO}

Um dos símbolos históricos e culturais do Brasil, o queijo artesanal é muitas vezes gerador de renda para pequenos produtores rurais. Produzido nas diferentes regiões do Estado, utiliza-se o leite cru como matéria-prima. O queijo é um alimento de grande importância nos hábitos de consumo dos brasileiros devido a sua rica composição nutricional e participação histórica na cultura nacional ${ }^{1,2}$. 
O norte de Minas Gerais é caracterizado como região de seca em longo período do ano e chuvas escassas; é uma região que os produtores optam por vacas da raça girolando, que destaca-se por suas características de produtividade, rusticidade, precocidade, longevidade e fertilidade, além da alta capacidade de adaptação a diferentes tipos de manejo e clima. As fêmeas girolando, produtoras de leite por excelência, possuem características fisiológicas e morfológicas perfeitas para a produção nos trópicos como, a capacidade e suporte de úbere, tamanho de tetas, fatores intrínsecos à lactação, pigmentação, capacidade termorreguladora, aprumos e pés fortes, conversão alimentar, eficiência reprodutiva, etc., possuindo um desempenho muito satisfatório economicamente ${ }^{3}$.

A elaboração de queijos artesanais é de grande importância social, cultural e econômica no estado de Minas Gerais. Confeccionados de maneira empírica nas pequenas propriedades rurais, cada família insere sua cultura e tradição na elaboração deste alimento, diversificando os queijos da região; esta atividade é responsável pela sustentabilidade de muitas dessas famílias de pequenos produtores ${ }^{4,5}$.

Os queijos artesanais são elaborados a partir do leite cru, relevante composição nutricional e alta disponibilidade de nutrientes como proteínas de alto valor biológico, cálcio, lipídios, lactose e vitaminas lipossolúveis, sendo um alimento de grande importância nos hábitos de consumo da população ${ }^{6}$.

A produção de queijos artesanais, em geral, é desprovida de mecanização, seguindo padrões históricos de elaboração e, geralmente, sem controle de qualidade durante a elaboração, podendo implicar em variações na qualidade físico-química desses produtos ${ }^{7,8}$.

Visando comparar a qualidade físico-química do mesmo tipo de queijo, porém produzido em diferentes regiões do Norte de Minas Gerais, o presente trabalho objetivou avaliar as características físico-químicas de queijos artesanais produzidos nas regiões.

\section{MATERIAIS E MÉTODOS}

Trata-se de um estudo de campo de caráter exploratório, com análise de dados quali-quantitativo e descritivo. As amostras foram escolhidas de forma aleatória e cunho de conhecimento de acadêmicos e familiares envolvidos na pesquisa. A amostragem foi selecionada de acordo com as comunidades com distância máxima de $170 \mathrm{~km}$ da cidade do estudo e que disponibiliza o produto para o comércio local. Foram incluídas todas as 
localidades, das quais os produtores aceitaram participar do estudo, e foram excluídos aquelas que não estavam presentes nos dias da coleta.

A coleta dos queijos artesanais foi realizada no período de janeiro a fevereiro de 2016 em quinze propriedades rurais, tradicionais, nas localidades de Bocaiúva, Mirabela, Janaúba, Guaraciama, Mucambo, Brasília de Minas, Pirapora, Francisco Sá, Juramento, Januária, São Pedro, Nova Esperança, Glaucilândia e São Francisco.

Foram coletados 15 queijos artesanais em quinze localidades diferentes, sendo um queijo por localidade, diretamente dos produtores em suas propriedades rurais, com 15 dias de maturação, estes queijos eram maturados sob refrigeração. Após adquiridos, foram transportados sob refrigeração a $4-10^{\circ} \mathrm{c}$ em caixas isotérmicas até o Laboratório de tecnologia de produtos vegetais. Não houve coleta de dados pessoais dos participantes.

A fim de determinar a composição química e propriedades físico-químicas dos queijos, foram pesados $250 \mathrm{~g}$ de cada amostra, em seguida foram raladas até a obtenção de massa homogênea, armazenadas e identificadas individualmente em potes de polietileno. Foram realizadas análises para determinações de $\mathrm{pH}$ e acidez titulável e teores percentuais de proteína, gordura, gordura no extrato seco e umidade. A determinação do $\mathrm{pH}$ foi realizada com auxílio de potenciômetro digital com eletrodo de vidro combinado (Analyser pH/lon 450 M - São Paulo, Brasil) e a acidez titulável expressa em ácido lático foi determinada por meio de titulação ácido-base. O percentual de proteínas foi determinado pelo método Kjeldahl (fator de conversão 6,38) e o percentual de gorduras foi obtido pelo método butirométrico. A determinação de umidade foi realizada pela secagem até obtenção de peso constante. A quantidade de gordura no extrato seco foi determinada por meio da razão entre teor de gordura e o extrato seco total do queijo. Todas as análises foram realizadas em triplicata de acordo com a legislação vigente ${ }^{9}$.

Os resultados de composição químicas e propriedades físico-químicas das amostras de queijos artesanais do Norte de Minas foram submetidas a análise estatística descritiva.

\section{RESULTADOS E DISCUSSÃO}

Foram encontrados os seguintes valores de acordo com a tabela 1: 
Tabela 1 - Composição físico-química das amostras de queijos artesanais produzidos em diferentes cidades do Norte de Minas Gerais

\begin{tabular}{crrrrr}
\hline Amostras & Proteína & \multicolumn{1}{c}{ Gordura } & Umidade & Acidez & $\mathrm{pH}$ \\
\hline $\mathbf{A}$ & 17,42 & 21,33 & 52,27 & 0,40 & 5,03 \\
$\mathbf{B}$ & 17,94 & 21,00 & 49,59 & 0,44 & 5,25 \\
$\mathbf{C}$ & 17,95 & 20,60 & 51,55 & 0,42 & 5,88 \\
$\mathbf{D}$ & 18,09 & 21,06 & 50,16 & 0,45 & 5,34 \\
$\mathbf{E}$ & 17,91 & 21,16 & 54,83 & 0,45 & 5,15 \\
$\mathbf{F}$ & 18,94 & 22,73 & 47,49 & 0,42 & 5,06 \\
$\mathbf{G}$ & 20,78 & 22,06 & 46,42 & 0,41 & 5,17 \\
$\mathbf{H}$ & 21,09 & 20,73 & 58,70 & 0,42 & 5,29 \\
$\mathbf{I}$ & 16,86 & 21,06 & 49,49 & 0,46 & 5,23 \\
$\mathbf{J}$ & 22,92 & 21,00 & 45,35 & 0,37 & 5,44 \\
$\mathbf{K}$ & 17,97 & 23,50 & 44,71 & 0,35 & 5,88 \\
$\mathbf{L}$ & 16,62 & 26,66 & 59,61 & 0,42 & 5,30 \\
$\mathbf{M}$ & 23,10 & 23,83 & 47,09 & 0,42 & 4,99 \\
$\mathbf{N}$ & 14,27 & 25,83 & 60,18 & 0,42 & 5,66 \\
$\mathbf{O}$ & 17,02 & 24,16 & 51,08 & 0,49 & 5,09 \\
\hline
\end{tabular}

Fonte: Dos Autores

Os teores de proteína dos queijos variaram entre 14,27 a 23,10\% já os teores de gordura e umidade variaram entre 20,6 a $26,66 \%$ e 44,71 a $60,18 \%$, respectivamente. $\mathrm{O}$ pH das amostras variou entre 4,99 a 5,88 e os valores de acidez entre 0,35 a 0,49\% de ácido lático.

As médias dos parâmetros físico-químicos encontrados nas análises de queijos artesanais do norte de Minas Gerais estão presentes na tabela 2.

Tabela 2. Valores médios das características físico-químicas de amostras de queijos artesanais produzidos em diferentes cidades do Norte de Minas Gerais

\begin{tabular}{lllllll}
\hline Amostras & Proteína $\%$ & Gordura $\%$ & GES $\%$ & Umidade $\%$ & Acidez & $\mathrm{pH}$ \\
\hline MED. & 18,59 & 22,45 & 46,69 & 51,23 & 0,42 & 5,25 \\
D.P & $\pm 5,06$ & $\pm 1,94$ & $\pm 8,21$ & $\pm 5,06$ & $\pm 0,01$ & $\pm 0,25$ \\
C.V & 0,129 & 0,086 & 0,175 & 0,098 & 0,045 & 0,049 \\
\hline
\end{tabular}

Fonte: Dos Autores

Legenda: $\mathrm{MED}=$ média, D.P = desvio padrão, C.V = coeficiente de variação

Apesar de serem da mesma região e localidades próximas, os queijos, apresentaram diferentes porcentagens de proteína resultado da elaboração artesanal, sem controle rígido das etapas do processo ${ }^{10}$. Alguns fatores podem ter contribuído para diminuir o rendimento desses queijos como o tipo de salga, o tempo de maturação, a redução da 
temperatura para coagulação do leite, corte com pá de madeira, mexedura incompleta ou excessiva, dieta dos animais. A quantidade em excesso de coalho adicionada à massa, pode ocasionar maior proteólise, implicando na redução do teor de proteínas ${ }^{11}$. Ao analisar queijo Minas Artesanal da Serra da Canastra, foram verificados teores de proteínas entre 23,50\% e $24,42 \%$, sendo valores próximos aos obtidos neste estudo para $26,66 \%$ das amostras ${ }^{12}$. Foram reportadas médias de proteínas em queijos Minas artesanais da Canastra de 23,9\% ${ }^{13}$. Existe grande variação no teor proteico de queijos tanto da mesma região produtora como da mesma propriedade, podendo ser observado neste estudo a variação no teor proteico de queijos do norte de Minas Gerais ${ }^{14}$. A falta de padronização nos processos, existente entre os produtores da mesma região dificulta a representatividade do tipo de queijo por região.

Os queijos apresentaram percentuais de gordura na faixa de 20,6 a 26,66\% sendo classificados como magros e semigordos, de acordo com conteúdo de matéria gorda no extrato seco $^{15}$. Essa variação nos percentuais de gordura dos queijos avaliados pode ser justificada devida a gordura no leite ser o componente mais variável, sendo influenciada por fatores - genéticos, ambientais, manejo, nutrição do animal, idade e raça ${ }^{16}$. Os percentuais de lipídios observados nas amostras estudadas são próximos aos valores obtidos por estudo que relatou teor de 26,34\% em queijos artesanais produzidos na microrregião de Montes Claros ${ }^{10}$. Contudo foram observados teores de lipídios entre 27,0\% e 29,5\% em queijos da Serra da Canastra, valores um pouco acima aos observados neste estudo ${ }^{12}$. Em estudo feito na região do Serro aponta queijos com o teor de gordura no extrato seco variando de 37,0 a $59,0 \%$ e o teor de proteína do queijo Canastra de 14,9 a 29,9 $9^{14}$. Essas diferenças observadas podem ser justificadas pelo diferente tipo de processamento utilizado, conforme a região de origem, e os hábitos populares característicos de cada uma delas ${ }^{17}$.

As amostras analisadas apresentaram diferentes teores de umidade, podendo os queijos serem classificados como de média, alta e de muito alta umidade ${ }^{15}$. O teor de umidade influencia diretamente na qualidade e as variações desse parâmetro nestes queijos podem estar ligadas ao processo de produção, à quantidade e ao tipo de salga, à pressão exercida no momento da prensagem e o tempo de maturação. A umidade pode influenciar também na textura e sabor do produto, dificultando este controle por se tratar de elaboração artesanal.

Os valores de $\mathrm{pH}$, na produção queijeira, são adotados com o objetivo de realizar o controle durante o armazenamento $^{18}$. O pH das amostras analisadas variou entre 4,99 e 5,88; 
essa variação pode ocorrer devido ao tempo e temperatura de processamento dos queijos. Por isso, o controle do $\mathrm{pH}$ durante o processo de elaboração e, em especial, nos primeiros dias de maturação, é de grande importância para assegurar a qualidade do produto ${ }^{19}$. Valores de $\mathrm{pH}$ deste estudo apresentaram-se próximo aos observados para os queijos artesanais analisados na microrregião de Montes Claros que foi de $5,36^{10}$. O leite usado na produção de queijos artesanais contribui diretamente nas características como o $\mathrm{pH}$, teor de gorduras e cálcio do produto final ${ }^{20}$.

A variação nos valores da acidez deve-se, provavelmente, a falta de padronização na salga ${ }^{10}$. O sal, além de conferir gosto característico ou realçar o sabor, complementa a dessoragem e regula acidez do queijo, favorecendo a liberação de água livre na massa pela diferença de pressão osmótica e a dissolução de algumas proteínas e seus produtos, os quais são substâncias tituláveis como ácidos ${ }^{21}$.

Definido pela Lei Estadual $\mathrm{n}^{\circ} 20.549$, de 18 de dezembro de 2012, como todo queijo confeccionado conforme a tradição histórica e cultural da região do Estado onde for produzido, a partir do leite integral da vaca, fresco e cru, sem nenhum tratamento térmico, retirado e beneficiado na propriedade de origem, que apresente consistência firme, cor e sabor próprios, massa uniforme, isenta de corante e conservantes, os queijos Minas Artesanais devem ter apenas ingredientes culturas láticas naturais como "pingo" (soro fermentado), coalho e $\mathrm{sal}^{22}$.

As variações nos resultados físico-químicos podem estar relacionadas a uma falta de uniformização e padronização dos métodos de elaboração destes produtos, já que são elaborados manualmente e estas famílias confeccionam os queijos de forma empírica preservando e a tradição da região ${ }^{23,24,2,25}$.

Por se tratar de um estudo de campo com amostras de origem cultural e produção artesanal os produtores locais não se mostram abertos a compartilhar fichas técnicas de preparo dos produtos visto que são de cunho pessoal e de interesse individual e resguardar sua identidade.

\section{CONCLUSÃO}

Pode-se concluir que queijos artesanais do Norte de Minas Gerais encontram-se dentro dos padrões físico-químicos, estabelecidos pela legislação vigente Instrução Normativa nº8 de 2006, caracterizando assim os queijos desta região. 
Há poucos estudos sobre queijos artesanais do norte de Minas Gerais, para comparação com este estudo, os resultados demonstram a falta de padronização na elaboração dos queijos artesanais relacionados a forma de elaboração destes produtos e que cada família insere sua cultura e tradição na elaboração deste alimento, diversificando os queijos da região; portanto é necessário continuar estudando e difundindo sobre os queijos artesanais e outros produtos que esta região pode oferecer.

\section{REFERÊNCIAS}

1. MIRANDA Gabriela Rigueira et al. Queijos artesanais: qualidade físico química e microbiológica e avaliação das condições higiênico-sanitárias dos manipuladores e ambiente de produção. Extensão rural. DEAR-CCR-UFSM. Santa Maria, v.23, n.1, 2016. Access in: 03 jun.2021.

2. KAMIMURA, Bruna et al. Brazilian artisanal cheeses: an overview of their characteristics, main types and regulatory aspects. Compr. Reviews in Food Science and Food Safety, v.18, p.1636-1657, 2019. doi: 10.1111/1541-4337.12486. Access in: 03 jun.2021.

3. REVISTA ATTALEA AGRONEGÓCIOS. Editora Attalea revista de agronegócios ltda-ISNN2236-5958 Franca (SP), 2020. Access in: 26 mai.2021.

4. LIMA, Camila et al. Bactérias do ácido láctico e leveduras associadas com o queijode-minas artesanal produzido na região da Serra do Salitre, Minas Gerais. Arquivo Brasileiro de Medicina Veterinária e Zootecnia, v.61, n.1, p.266-272, 2009. doi.org/10.1590/S0102-09352009000100037. Access in: 26 mai.2021.

5. ALMEIDA, Anna Cristina et al. Caracterização da produção de queijo artesanal na região de Montes Claros, norte de Minas Gerais. Acta Veterinária Brasílica, v.6, n.4, p.312-320, 2012. https://doi.org/10.21708/avb.2012.6.4.2924. Access in: 26 mai.2021.

6. OLIVEIRA, Laura Maria et al. Avaliação da qualidade de queijos ralados para proteção à saúde pública. Revista do Instituto de Laticínios Cândido Tostes, v. 67, n.384, p. 41-47, 2012. https://doi.org/10.5935/2238-6416.20120006. Access in: 26 mai.2021.

7. BORELLI, Beatriz Martins et al. Yeast populations associated with the artisanal cheese produced in the region of Serra da Canastra, Brazil. World Journal Microbiology and Biotechnology, v.22, p.1115-1119, 2006. doi: $10.1007 / \mathrm{s} 11274-$ 006-9151-3. Access in: 27 mai.2021.

8. BRANT, Laura Misk Faria; FONSECA, Leorges Moraes; SILVA, Miriam Cristina Carlos. Avaliação da qualidade microbiológica do queijo-de-minas artesanal do Serro- 
MG. Arquivo Brasileiro de Medicina Veterinária e Zootecnia, v.59, n. 6, P.15701574, 2007. https://doi.org/10.1590/S0102-09352007000600033. Access in: 27 mai.2021.

9. MINISTÉRIO DA AGRICULTURA E PECUÁRIA E ABASTECIMENTO (BR). Departamento de Inspeção de Produtos de origem Animal. Instrução Normativa $n^{\circ} 68$ de 12 de dezembro de 2006. Métodos analíticos oficiais físico-químicos, para controle de leite e produtos lácteos. Diário Oficial da República Federativa do Brasil, Brasília, DF, 14 de dez. 2006. Access in: 27 mai.2021.

10. LEMPK, Marcus Welbert. Caracterização físico-química, microbiológica e tecnológica do queijo artesanal da microrregião de Montes Claros - MG. 2013. 91 p. Dissertação (Mestrado em Ciências Agrárias), Universidade Federal de Minas Gerais, Montes Claros, MG, 2013. Access in: 03 jun.2021.

11. COELHO, Sandra Gesteira et al. Manipulação da composição do leite a partir de fatores nutricionais. Caderno de Ciências Agrárias, Montes Claros, v. 2, n. 2, 2010. Access in: 27 mai.2021.

12. RESENDE, Maria Fatima Silva. Queijo minas artesanal da serra da canastra: influência da altitude e do nível de cadastramento das queijarias nas características físico-químicas e microbiológicas. 2010. 72 p. Dissertação (Mestrado em Ciência Animal). Universidade Federal de Minas Gerais, Belo Horizonte, 2010. Access in: 27 mai.2021.

13. SILVA, Jonas Guimarães et al. Características físico-químicas do queijo Minas artesanal da Canastra. Revista do Instituto de Laticínios Cândido Tostes, v. 66, n. 380, p. 16-22, 2011. Access in: 27 mai.2021.

14. PINTO, Maximiliano Soares. Diagnóstico socioeconômico, cultural e avaliação dos parâmetros físico-químicos e microbiológicos do Queijo Minas Artesanal do Serro. 2004. 134 p. Dissertação (Mestrado em Ciência e Tecnologia de Alimentos) Universidade Federal de Viçosa, Viçosa, 2004. Access in: 27 mai.2021.

15. BRASIL. Portaria n. 146, de 07 de março de 1996. Regulamentos Técnicos de Identidade e Qualidade dos Produtos Lácteos. Ministério da Agricultura e do Abastecimento. Secretaria Nacional de Inspeção de Produtos de Origem Animal. Diário Oficial da União, Brasília, DF, 11 mar. 1996. Access in: 27 mai.2021.

16. NUNES, Augusto Cesar Magalhães et al. Qualidade físico-química e microbiológica de queijos ralados comercializados em Recife-PE, Brasil. Journal of Bioenergy and Food Science, v.2, p. 25-31, 2015. doi: 10.18067/jbfs.v2i1.10. Access in: 03 jun.2021. 
17. OLIVEIRA, Debora Francielly et al. Caracterização físico-química de queijos Minas artesanal produzidos em diferentes microrregiões de minas gerais. Oikos: Revista Brasileira de Economia Doméstica, v. 24, n. 2, p. 185-196, 2013. Access in: 03 jun.2021.

18. CORREIA, Paula et al. Influence of different processing parameters in physical and sensorial properties of Serra da Estrela cheese. Journal of Hygienic Engineering and Design, v. 8, p. 135-140, 2014. Access in: 03 jun.2021.

19. DIAS, Bruna Ferreira et al. Qualidade microbiológica e físico-química de queijo minas frescal artesanal e industrial. Revista de Agricultura Neotropical, v. 3, p. 57 64, 2016. doi: : 10.32404/rean.v3i3.1211. Access in: 03 jun.2021.

20. PINTO, Maximilano Soares et al. Características físico-químicas e microbiológicas do queijo artesanal produzido na microrregião de Montes Claros - MG. Revista do Instituto de Laticínios Cândido Tostes, v. 71, n. 1, p. 43-52, 2016. https://doi.org/10.14295/2238-6416.v70i1.514. Access in: 03 jun.2021.

21. NHUCH, Elsa et al. Caracterização dos queijos artesanais produzidos em Viamão, no estado do Rio Grande do Sul, quanto à evolução físico-química e microbiológica. Veterinária em foco, v.2, n.1, p15-24, 2004. Access in: 03 jun.2021.

22. MINAS GERAIS. ASSEMBLÉIA LEGISLATIVA DO ESTADO DE MINAS GERAIS. Lei $\mathrm{n}^{\circ}$ 20.549, de 18 de dezembro de 2012. Dispõe sobre a produção e a comercialização dos queijos artesanais de Minas Gerais. Diário do Executivo. Belo Horizonte, 19 dez. 2012. p. 1 col. 2. Disponível em: <http:// www.almg.gov.br/consulte/legislacao>. Access in: 03 jun.2021.

23. QUEIROGA, Rita Cassia Ramos de Egypto et al. Elaboração e caracterização físicoquímica, microbiológica e sensorial de queijo "tipo minas frescal" de leite de cabra condimentado. Revista Ciência Agronômica, v. 40, p. 363-372, 2009. Access in: 26 mai.2021.

24. SOARES, Driene Bastos et al. Análise sanitária e físico-química e adequação bacteriológica do queijo minas artesanal produzido em duas propriedades. Ciência animal brasileira, Goiânia, v.19, p:1-13, 2018. https://doi.org/10.1590/18096891v19e-36499. Access in: 03 jun.2021.

25. ARAÚJO, João Paulo Andrade et al. Uma análise histórico-crítica sobre o desenvolvimento das normas brasileiras relacionadas a queijos artesanais. Medicina Veterinária. Arquivo Brasileiro de Medicina Veterinária e Zootecnia. v.72, n.5, 2020. https://doi.org/10.1590/1678-4162-11766. Access in: 03 jun.2021. 